\title{
Is sadness blue? The problem of using figurative language for emotions on psychological tests
}

\author{
Kimberly A. Barchard ${ }^{1}$ Kelly E. Grob ${ }^{1} \cdot$ Matthew J. Roe ${ }^{2}$
}

Published online: 2 March 2016

(C) Psychonomic Society, Inc. 2016

\begin{abstract}
Psychological tests sometimes include figurative language like I feel blue. However, figurative language may not mean the same thing cross-culturally. Previous research found cross-cultural evidence for 14 conceptual metaphors and metonymies for emotions (e.g., sadness is blue). Our two studies asked participants (total $n=795$ ) in the USA and India whether happiness, sadness, anger, and fear are associated with certain descriptors (blue, down, bright, etc.). Most participants in both countries endorsed ten of the 14 hypothesized associations; however, the percentage of participants endorsing an association was often far from $100 \%$. For example, in the USA, only $71.7 \%$ associated hot with anger and only $65.9 \%$ associated blue with sadness. Moreover, descriptors were often associated with more than one emotion. Furthermore, only two associations (happiness is up and bright) were endorsed by more than $90 \%$ of participants in both countries and had descriptors that were not associated with additional emotions. We conclude that figurative language is often ambiguous and should be used with caution on psychological tests unless there is evidence the language is understood cross-culturally. Advice to this effect is currently lacking from psychometrics textbooks and should be added.
\end{abstract}

Electronic supplementary material The online version of this article (doi:10.3758/s13428-016-0713-5) contains supplementary material, which is available to authorized users.

Kimberly A. Barchard

kim.barchard@unlv.edu

1 Department of Psychology, University of Nevada, Las Vegas, NV, USA

2 Department of Management, Entrepreneurship, and Technology, University of Nevada, Las Vegas, NV, USA
Keywords Test design · Conceptual metaphors · Figurative language $\cdot$ Cross-cultural testing $\cdot$ Emotion

\section{Introduction}

When people describe emotions in songs and literature, they often use figurative language. For example, Jane Porter (1807) wrote, "Happiness is a sunbeam ...when it strikes on a kindred heart, like the converged light on a mirror, it reflects itself with redoubled brightness" (p. 81). Figurative language is also common in everyday speech (Fainsilber \& Ortony, 1987). People might say, I'm feeling up, she had cold feet, or he was hot-headed. Indeed, figurative language appears to be embedded in how people think (Lakoff, 2014). Not surprisingly, figurative language sometimes creeps into psychological tests related to emotions. For example, figurative language occurs in the Beck Depression Inventory (wound up; Beck, 1972), the Center for Epidemiologic Studies Depression Scale (CES-D; blue; Eaton, Muntaner, Smith, Tien, \& Ybarra, 2004; Radloff, 1977), the Positive and Negative Affect Schedule - Expanded Form (PANAS-X; blue, downhearted, sluggish, sheepish; Watson \& Clark, 1994; Watson, Clark, \& Tellegan, 1988), and Hogan's Empathy Scale (on top of the world, short tempered; Hogan, 1969). Even the word depression is figurative language: If this word appeared on an emotion test, it would not be interpreted literally as a shallow hole in the ground or at least, we hope it would not.

There are several types of figurative language. In the quote above, happiness is a sunbeam is a metaphor; it says that one thing (happiness) is the same as another (a sunbeam). Happiness is like the converged light on a mirror is a simile; it says that one thing (happiness) is like another (light). Kindred heart is a metonymy; it uses one thing (a heart) to stand for something it is closely associated with (emotions). 
Metonymies are often used to describe emotions. For example, when people are sad, they tend to have slouched body postures and the corners of their mouths tend to turn downwards (Lakoff \& Johnson, 1980). From this, people come to associate a downward orientation with sadness, thus leading to phrases such as "I'm feeling down" (Lakoff \& Johnson, 1980, p. 15), in which the descriptor down can stand for the target emotion sadness (Kövecses, 2013). When people generalize from the metonymy to other features of the descriptor (things that are not inherently associated with that emotion), conceptual metaphors are created (Kövecses, 2013). For example, people might say they are "in the pits" (p. 79) or "down in the dumps" (p. 79), even though people are not usually located in holes in the ground when they are sad. These instances of figurative language are based upon the conceptual metaphor sadness is down. Thus, conceptual metaphors underlie multiple instances of figurative language (such as ordinary metaphors and similes).

Figurative language can be helpful because it is often the easiest way to explain abstract concepts such as emotions. However, it is also more likely to be misunderstood than literal language. When figurative language appears in psychological tests, it might be misinterpreted for three reasons. First, some test takers may be completing a test that is not written in their native language. When people are learning a new language, they gain grammatical and communicative proficiency first and may not learn figurative language or metaphorical concepts until much later (Danesi, 1992). Second, figurative language varies from one country to another. Because of this, translators must take great care to ensure that the original meaning is preserved (Corral \& Landrine, 2009; Matsumoto \& Yoo, 2007). For example, calling someone a bear in Chinese is a way of implying they are incompetent (Wang, Wang, \& Xing, 2011), but this implication does not hold in the USA. Even when two countries use the same language, figurative language may vary. For example, consider the different meanings of braces, lift, and rubber in the USA and the UK (Lovett, 2013). Finally, even if a test taker is familiar with the figurative language, they may interpret it in a different way than the test designer intended, because figurative language often has many interpretations (Partridge, 2006).

When talking in person, it is fairly easy to resolve miscommunications caused by the use of figurative language. However, when figurative language is embedded in a written psychological test, the test administrator is unlikely to realize a test taker is misinterpreting some phrases. At a minimum, such misinterpretations could add random variation to the test scores, making the test less reliable and valid for those test takers. At worst, these misinterpretations could systematically raise or lower test scores, causing test bias.

Test designers do not appear to be aware of this issue. This is evident from the fact that some of our most respected tests of emotions include figurative language. Books that explain test design do extol the importance of writing test content that is clear and unambiguous (Hogan, 2015; Kline, 2005; Kubiszyn \& Borich, 2007; McIntire \& Miller, 2007; Salkind, 2006), but they do not generally warn test designers against using figurative language. We examined dozens of psychometrics books and only two of them addressed the issue of figurative language, and then only obliquely: They said that test designers should avoid "specific linguistic constructions" (Aiken \& Groth-Marnat, 2006, p. 138) and "slang or colloquial language" (McIntire \& Miller, 2007, p. 376).

We three came to appreciate the problem of test bias when we were designing a new test of emotion perception. Due to increasing globalization, people in the USA come from many different countries and cultures. Contrary to the image of the USA being a melting pot, fully $20 \%$ of US residents do not speak English at home (United States Census Bureau, 2012a). Moreover, with the increasing use of English around the world, English-language psychological tests are likely to be used in many countries. We therefore tried to write test items that would be culture fair. While writing items, we identified a possible source of test bias: cross-cultural differences in the emotional connotations of non-emotion words. We therefore conducted an extensive literature search on conceptual metaphors for emotions and tried to avoid culturally specific language. However, when we stared at our final items, a niggling worry persisted: Were the emotional connotations of these non-emotion words really the same? Would people from different cultures really give the same interpretations to our items - or items on other psychological tests related to emotions? This paper documents our attempt to answer these questions.

Rather than examining the items on one specific test, we took the more general approach of studying conceptual metaphors and metonymies for emotions. In this way, we hoped to determine which figurative language for emotions can safely be used in psychological tests. We asked participants which descriptors (e.g., up vs. down) are associated with target emotions (e.g., happiness). If almost all people associate the descriptor with one emotion, it can be used unambiguously on psychological tests.

\section{Selecting conceptual metaphors and metonymies}

To identify metonymies and conceptual metaphors for emotions, we conducted a review of previous research. We located support for 14 metonymies and conceptual metaphors for emotions in the USA: Happiness is associated with up, bright, and warm; sadness is associated with down, dark, blue, and empty; anger is associated with hot, red, and dark; and fear is associated with white, cold, dark, and being paralyzed. Ten of these associations have also been identified in three or more other countries (see Table 1).

These associations have usually been found using lexical analyses. In a lexical analysis, researchers identify commonly used figurative language in a specific culture and then deduce 
Table 1 Support for conceptual metaphors and metonymies

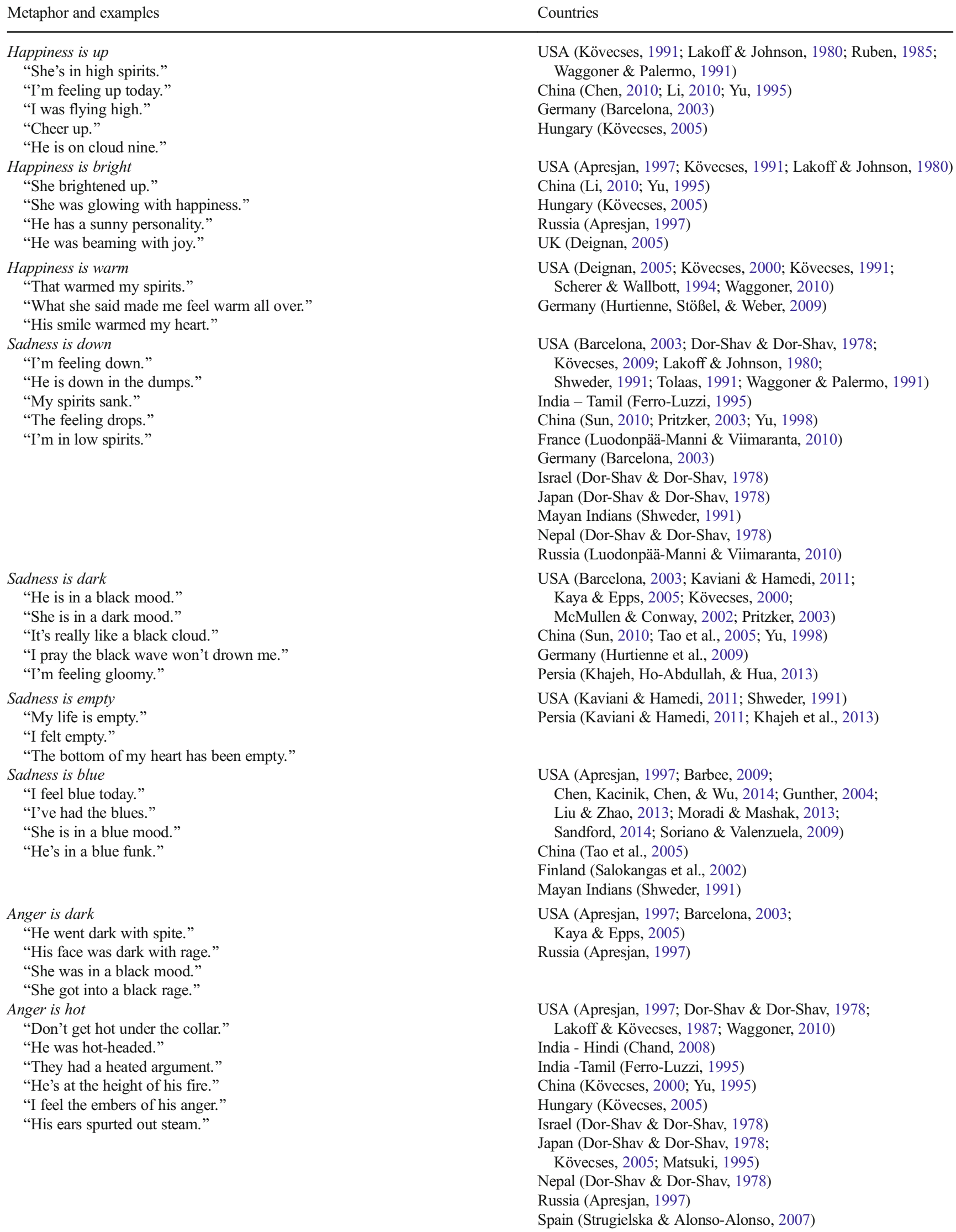

USA (Kövecses, 1991; Lakoff \& Johnson, 1980; Ruben, 1985; Waggoner \& Palermo, 1991)

China (Chen, 2010; Li, 2010; Yu, 1995)

Germany (Barcelona, 2003)

Hungary (Kövecses, 2005)

USA (Apresjan, 1997; Kövecses, 1991; Lakoff \& Johnson, 1980) China (Li, 2010; Yu, 1995)

Hungary (Kövecses, 2005)

Russia (Apresjan, 1997)

UK (Deignan, 2005)

USA (Deignan, 2005; Kövecses, 2000; Kövecses, 1991; Scherer \& Wallbott, 1994; Waggoner, 2010)

Germany (Hurtienne, Stößel, \& Weber, 2009)

USA (Barcelona, 2003; Dor-Shav \& Dor-Shav, 1978;

Kövecses, 2009; Lakoff \& Johnson, 1980;

Shweder, 1991; Tolaas, 1991; Waggoner \& Palermo, 1991)

India - Tamil (Ferro-Luzzi, 1995)

China (Sun, 2010; Pritzker, 2003; Yu, 1998)

France (Luodonpää-Manni \& Viimaranta, 2010)

Germany (Barcelona, 2003)

Israel (Dor-Shav \& Dor-Shav, 1978)

Japan (Dor-Shav \& Dor-Shav, 1978)

Mayan Indians (Shweder, 1991)

Nepal (Dor-Shav \& Dor-Shav, 1978)

Russia (Luodonpää-Manni \& Viimaranta, 2010)

USA (Barcelona, 2003; Kaviani \& Hamedi, 2011; Kaya \& Epps, 2005; Kövecses, 2000;

McMullen \& Conway, 2002; Pritzker, 2003)

China (Sun, 2010; Tao et al., 2005; Yu, 1998)

Germany (Hurtienne et al., 2009)

Persia (Khajeh, Ho-Abdullah, \& Hua, 2013)

USA (Kaviani \& Hamedi, 2011; Shweder, 1991)

Persia (Kaviani \& Hamedi, 2011; Khajeh et al., 2013)

USA (Apresjan, 1997; Barbee, 2009;

Chen, Kacinik, Chen, \& Wu, 2014; Gunther, 2004;

Liu \& Zhao, 2013; Moradi \& Mashak, 2013;

Sandford, 2014; Soriano \& Valenzuela, 2009)

China (Tao et al., 2005)

Finland (Salokangas et al., 2002)

Mayan Indians (Shweder, 1991)

USA (Apresjan, 1997; Barcelona, 2003;

Kaya \& Epps, 2005)

Russia (Apresjan, 1997)

USA (Apresjan, 1997; Dor-Shav \& Dor-Shav, 1978;

Lakoff \& Kövecses, 1987; Waggoner, 2010)

India - Hindi (Chand, 2008)

India -Tamil (Ferro-Luzzi, 1995)

China (Kövecses, 2000; Yu, 1995)

Hungary (Kövecses, 2005)

Israel (Dor-Shav \& Dor-Shav, 1978)

Japan (Dor-Shav \& Dor-Shav, 1978;

Kövecses, 2005; Matsuki, 1995)

Nepal (Dor-Shav \& Dor-Shav, 1978)

Russia (Apresjan, 1997)

Spain (Strugielska \& Alonso-Alonso, 2007) 
Table 1 (continued)

\begin{tabular}{|c|c|}
\hline Metaphor and examples & Countries \\
\hline & $\begin{array}{l}\text { UK (Gibbs, 1994) } \\
\text { Wolof language (Kövecses, 2005) } \\
\text { Zulu language (Kövecses, 2005) }\end{array}$ \\
\hline $\begin{array}{l}\text { Anger is red } \\
\text { "His face turned red." } \\
\text { "She was scarlet with rage." } \\
\text { "He saw red." } \\
\text { "His eyes emit fire." } \\
\text { "He turned red with anger." } \\
\text { "Red coal." }\end{array}$ & $\begin{array}{l}\text { USA (Chen et al., 2014; Fetterman et al., 2012; } \\
\quad \text { Kövecses, 2005; Lakoff \& Kövecses, 1987; } \\
\text { Waggoner \& Palermo, 1989) } \\
\text { India (Kennedy, 2011) } \\
\text { China (Chen et al., 2014; Kövecses, 2005; Yu, 1995) } \\
\text { Hungary (Kövecses, 2005) } \\
\text { Japan (Kövecses, 2005; Matsuki, 1995) } \\
\text { Poland (Mikolajczuk, 1998) } \\
\text { Zulu language (Kövecses, 2005) }\end{array}$ \\
\hline $\begin{array}{l}\text { Fear is dark } \\
\text { "He told me his darkest fears." }\end{array}$ & USA (Barcelona, 2003; Kaya \& Epps, 2005) \\
\hline $\begin{array}{l}\text { Fear is cold } \\
\text { "The blood freezes in the veins." } \\
\text { "He felt cold shivers running down his spine." } \\
\text { "I was filled with icy fear." } \\
\text { "She felt cold steely horror." } \\
\text { "The cold knives of fear." }\end{array}$ & $\begin{array}{l}\text { USA (Dobrovol'skiī, \& Piirainen, 2005; } \\
\text { Dor-Shav \& Dor-Shav, 1978; Kövecses, 1990; } \\
\text { Omori, 2008; Scherer \& Wallbott, 1994; Waggoner, 2010) } \\
\text { China (Yu, 2002) } \\
\text { Dutch language (Dobrovol'skiĭ \& Piirainen, 2005) } \\
\text { Hungary (Dobrovol'skiï \& Piirainen, 2005) } \\
\text { Israel (Dor-Shav \& Dor-Shav, 1978) } \\
\text { Japan (Dor-Shav \& Dor-Shav, 1978) } \\
\text { Nepal (Dor-Shav \& Dor-Shav, 1978) } \\
\text { Russia (Apresjan, 1997; Dobrovol'skiĩ \& Piirainen, 2005) } \\
\text { UK (Omori, 2008) }\end{array}$ \\
\hline $\begin{array}{l}\text { Fear is paralyzed } \\
\text { "He became paralyzed by fear." } \\
\text { "He was petrified with fear." } \\
\text { "His soul was bound by fear." } \\
\text { "My heart stopped beating." }\end{array}$ & $\begin{array}{l}\text { USA (Davitz, 1969; Kövecses, 1990) } \\
\text { Arabic language (Maalej, 2007) } \\
\text { Poland (Strugielska \& Alonso-Alonso, 2007) } \\
\text { Russia (Apresjan, 1997) } \\
\text { Spain (Strugielska \& Alonso-Alonso, 2007) }\end{array}$ \\
\hline $\begin{array}{l}\text { Fear is white } \\
\text { "His face was pale out of fright." } \\
\text { "His face lost its color." } \\
\text { "He turned white with fear." } \\
\text { "White as a sheet." } \\
\text { "White as a ghost." }\end{array}$ & $\begin{array}{l}\text { USA (Apresjan, 1997; Oster, 2010; Zavyalova, 2013) } \\
\text { Persia (Maalej, 2007) } \\
\text { Poland (Strugielska \& Alonso-Alonso, 2007) } \\
\text { Russia (Apresjan, 1997) } \\
\text { UK (Strugielska \& Alonso-Alonso, 2007; Zavyalova, 2013) }\end{array}$ \\
\hline
\end{tabular}

the conceptual metaphors that underlie that language (Kövecses, 1986). For example, in the USA, people sometimes say, "The thought chilled him," "He had cold feet," or "Cold shivers ran down her spine" (Kövecses, 2009, p. 81). From these, researchers deduce that fear is cold in the USA.

While lexical analyses can find commonly used figurative language in different countries, these analyses do not indicate how many people understand or use this language in each country. To determine what proportion of a population associates a certain descriptor (e.g., cold) with a target concept (e.g., fear), researchers can ask them explicitly. For example, Waggoner (2010) asked participants in the USA if certain emotions were associated with specific temperatures. He found that adults commonly associated anger with hot, happiness with warm, and fear and sorrow with cold. In the current studies, we extended this research by examining the evidence for a wider range of associations and by including a second country.

\section{Selecting countries}

We collected data in the USA and India. We selected India as the second country for three reasons. First, both the USA and India have large numbers of users on Amazon Mechanical Turk (a website that can be used for participant recruitment), making it feasible to obtain large samples (Ross, Irani, Silberman, Zaldivar, \& Tomlinson, 2010). Second, India has a large English-speaking population (in fact, English is the subsidiary official language; Department of Official Language, 2011), and this population might be given tests that are written in English because validated tests in the person's first language may not exist. Third, India is culturally and socially different from the USA. It has different ethnic groups (India is $72 \%$ Indo-Aryan and $25 \%$ Dravidian; the USA is $63.7 \%$ White, $16.3 \%$ Hispanic or Latino, and $12.6 \%$ Black), religions (79.6\% Hindu and 14.2\% Muslim vs. $86.2 \%$ Christian with $24.5 \%$ Catholic and $15.8 \%$ Baptist), 
population densities ( 382 people $/ \mathrm{km}^{2}$ vs. 87.4 ), and rural/ urban mix (68.8 \% rural vs. $21 \%$ ) (Census of India, 2011; United States Census Bureau, 2012b). India also is a more closely integrated society (moderate collectivism vs. high individualism) with greater differences in power among individuals (relatively high power distance vs. moderate power distance; Hofstede, 1983). Choosing a country that is so different from the USA provides a better test of whether the associations with emotions are universal and can be used on psychological tests without causing test bias.

\section{Hypotheses}

We hypothesized that the above-mentioned 14 associations would be common (endorsed by more than $50 \%$ of participants) in the USA: Happiness would be commonly associated with up, bright, and warm; sadness with down, dark, empty, and blue; anger with dark, hot, and red; and fear with dark, white, paralysis, and cold. Because some of these associations have been found in at least one other country and because some of them might plausibly be due to common physiological reactions to emotional experiences, we hypothesized that most of these same associations would be common in India. We were uncertain, however, if any of these descriptors would be associated with any of the emotions by the vast majority of participants (e.g., more than $90 \%$ ) and would be safe to use on psychological tests.

\section{Study 1}

\section{Method}

Procedures Participants were recruited through a short advertisement on Amazon Mechanical Turk (MTurk). MTurk is an English-language crowd-sourcing website that allows researchers to advertise studies to potential participants. An increasing number of behavioral studies are being advertised on MTurk (Paolacci \& Chandler, 2014), because it is a quick and easy way to obtain large samples (Buhrmester, Kwang, \& Gosling, 2011). MTurk users provide high quality data: Participants provide consistent and verifiable answers (Rand, 2012) that result in high reliability (Buhrmester et al., 2011) and replication of cognitive and behavioral findings from laboratory testing and college samples (Paolacci \& Chandler, 2014; Sprouse, 2011).

MTurk may be a better source of participants than traditional university subject pools for three reasons. First, college students are often required to do research studies for course credit, which they receive regardless of the quality of their data. In contrast, MTurk workers are primarily motivated by being paid for their work (Antin \& Shaw, 2012) and are therefore concerned about protecting their online reputation so that they can get access to good, high-paying work (Gupta, Martin, Hanrahan, \& O’Neill, 2014). As a result, we think MTurk workers may take studies more seriously. Second, MTurk samples are more diverse than college student samples (Mason \& Suri, 2011; Paolacci \& Chandler, 2014) and other Internet samples (Buhrmester et al., 2011), making them more representative of the USA population. Third, MTurk allows researchers to restrict participants to those with certain qualifications, such as people who live in certain countries, thus facilitating crosscultural research (Amazon Web Services, 2014).

For most tasks on MTurk (including research studies), users are paid a nominal fee. Therefore, participants were given a validation code at the end of our 5-min survey. When they entered the code into a textbox on the MTurk website, they were paid 20 cents. Litman, Robinson, and Rosenzweig (2015) showed that compensation in this range is sufficient to ensure high quality data in both the USA and India.

Participants Participants were recruited from the USA and India. Participants were only allowed to participate in the study if they claimed to live in the USA or India and if their computer's IP address was from one of these two countries.

Initially, there were 219 participants (115 male, 104 female) from the USA and 362 (212 male, 150 female) from India. To ensure that participants understood the study and the items, we asked participants how comfortable they were reading, writing, speaking, and listening to English, using ratings that ranged from 1 (Very uncomfortable, it's a real struggle) to 10 (Perfectly comfortable). We only analyzed the data from participants who indicated that they were very comfortable with English (at least 9 out of 10) on all four items. The first author has used this exact filtering method in every one of her studies on emotional intelligence and thus knew from the beginning of data collection that this filtering method would be used.

The final sample included 205 people from the USA and 161 people from India. Originally, we had aimed for samples of 200 from each country. However, given that only 107 people are needed from each country to have power of .80 for a medium effect using a chi-square test of independence (Cohen, 1992), these sample sizes were considered adequate.

The participants from the USA were equally divided between male and female (103 male, 102 female) and they ranged in age from 18 to 64 years $($ mean $=32.8, \mathrm{SD}=11.0$ ). Most participants identified themselves as White (82.4\%), Black or African American (11.7 \%), or Asian (5.9\%). Most spoke English as their first language (95.6\%).

The participants from India were predominantly male (100 male, 61 female). They ranged in age from 19 to 61 years (mean $=31.4, \mathrm{SD}=8.8$ ). Most identified themselves as Asian $(94.4 \%)$. About a quarter spoke English as their first language $(24.2 \%)$. Their next most common first languages were Malayalam (19.9\%), Tamil (19.9\%), and Hindi (17.4\%). 


\section{Measures}

Language of emotions questionnaire We modeled the Language of Emotions Questionnaire (LEQ) after the measure used by Waggoner (2010), which asked if certain emotions "corresponded" (p. 237) to different temperatures. The LEQ expands upon Waggoner's measure by examining a wider range of descriptors: those identified in previous research on conceptual metaphors for happiness, sadness, anger, and fear (e.g., up, down, bright, dark, etc.; see Table 1). Like Waggoner, we asked participants if the descriptors "corresponded" (p. 237) to the emotions. For example, does the descriptor up correspond to happiness? For each emotion, there were six items. For most items, participants were instructed to choose one of the adjectives (up or down; dark or bright; empty or full; paralyzed or able to move; and hot, warm, cool, or cold). For the last item, participants were allowed to select multiple colors.

\section{Results and discussion}

In the USA, the majority of participants indicated that the target emotion was associated with the intended descriptor for 13 of the 14 associations (see Tables 2, 3, and 4). These results indicate that people in the USA commonly understand the majority of these associations, providing additional support for these metonymies and conceptual metaphors. In India, fewer participants indicated that the target emotions were

Table 2 Percentages of people indicating that the emotion corresponds to specific temperatures, Study 1

\begin{tabular}{lcccc}
\hline Emotion & Hot & Warm & Cool & Cold \\
\hline Happiness & & & & \\
USA & 21.1 & $73.0+*$ & 5.4 & 0.5 \\
India & 9.3 & 30.4 & 36.0 & 24.2 \\
Sadness & & & & \\
USA & 2.0 & 4.4 & 34.6 & $59.0+*$ \\
India & 21.7 & 28.6 & 19.3 & 30.4 \\
Anger & & & & \\
USA & $71.7+*$ & 3.4 & 4.4 & 20.5 \\
India & $66.9+$ & 13.8 & 8.1 & 11.3 \\
Fear & & & & \\
USA & 6.3 & 5.4 & 22.4 & $65.9+*$ \\
India & 24.4 & 28.8 & 11.3 & 35.6 \\
\hline
\end{tabular}

Notes. Predicted associations are shown in italic font. The margin of error for any proportion can be calculated as $1.96 \sqrt{p(1-p) / n}$.

+ This percentage is significantly $(p<.05)$ greater than $50 \%$ (directional), according to the chi-square test.

*The percentage for this country is significantly $(p<.05)$ higher than the percentage for the other country, according to Fisher's exact test of independence associated with the intended descriptors. This led us to divide the metonymies and conceptual metaphors into those that might be universal (and so might be safe to use on psychological tests) and those that appear to be culture-specific, providing interesting insights for the field of cognitive linguistics (Tendahl \& Gibbs, 2008).

Ten of the fourteen associations were endorsed in both the USA and India. These metonymies and conceptual metaphors seem like good candidates for universality, given how strong these associations were in this study and given that these associations have also been found in previous research. First, we found strong evidence that happiness is bright and that negative emotions (anger, sadness, and fear) are dark. Across both the USA and India, at least $87 \%$ of participants endorsed these associations, echoing previous research in the USA, China, Germany, Hungary, Persia, Russia, and the UK (see Table 1). We consider these to be sizable percentages, especially given that facial expressions for emotion are said to be universally recognized even though only $81.5 \%$ of people on average select the target emotion (Russell, 1991). Darkness may be associated with negative emotions and brightness with positive emotions because darkness tends to lead to physical unease and melancholy, whereas brightness tends to lead to feeling confident, safe, and healthy (Barcelona, 2003).

Second, we found strong evidence that anger is associated with red and hot. Across both countries, at least $66 \%$ of participants endorsed these associations. Given that color and temperature choices were not dichotomous (nine colors and four temperatures were listed), these percentages are impressively high. These results are congruent with extensive research in the USA showing that anger is associated with red and hot, as well as similar research in China, Hungary, Israel, Japan, Nepal, Russia, Spain, the UK, Wolof people, and Zulu people (see Table 1). These results are also congruent with three studies from India. First, Chand (2008) conducted a lexical analysis comparing conceptual metaphors in Hindi to English and found that the conceptual metaphor anger is heat is quite common in Hindi, as when referring to an angry person as "boiling or swelling with emotion" (p. 11). Second, Ferro-Luzzi (1995) conducted another lexical analysis, this time of a single Tamil writer (L. S. Ramamirtham), and found anger was associated with hot: "his ears spurted out steam" (p. 189) and fury burnt in their eyes "like live embers covered by ashes" (p. 189). Third, Kennedy (2011) conducted an informal study of figurative language through the Internet and found that the Hindi phrase "लाल कोयला" [which translates as red coal] means to be flushed with anger. The associations of anger with red and hot are consistent with the conceptual metaphor, Anger is a hot fluid in a container, which has been found in English, Chinese, Hungarian, and Japanese (Kövecses, 2000). For example, when anger becomes more intense, fluid rises ("His pent-up anger welled up inside him"; Kövecses, p. 162) and steam is produced 
Table 3 Percentages of people indicating that the emotion corresponds to dichotomous descriptors, Study 1

\begin{tabular}{|c|c|c|c|c|c|c|c|c|}
\hline Emotion & Up & Down & Dark & Bright & Empty & Full & Paralyzed & Able to move \\
\hline \multicolumn{9}{|c|}{ Happiness } \\
\hline USA & $99.5+$ & 0.5 & 0.0 & $100.0+*$ & 2.5 & $97.5+$ & 1.0 & $99.0+*$ \\
\hline India & $98.8+$ & 1.2 & 5.0 & $95.0+$ & 5.1 & $94.9+$ & 12.5 & $87.5+$ \\
\hline \multicolumn{9}{|l|}{ Sadness } \\
\hline USA & 1.0 & $99.0+$ & $98.5+*$ & 1.5 & $91.7+$ & 8.3 & $87.8+$ & 12.2 \\
\hline India & 3.1 & $96.9+$ & $93.1+$ & 6.9 & $93.1+$ & 6.9 & $84.5+$ & 15.5 \\
\hline \multicolumn{9}{|l|}{ Anger } \\
\hline USA & 16.3 & $83.7+*$ & $93.7+*$ & 6.3 & $57.1+$ & 42.9 & 52.7 & 47.3 \\
\hline India & 26.3 & $73.8+$ & $87.4+$ & 12.6 & $70.4+*$ & 29.6 & $63.1+$ & 36.9 \\
\hline \multicolumn{9}{|l|}{ Fear } \\
\hline USA & 6.9 & $93.1+$ & $99.5+*$ & 0.5 & $71.6+$ & 28.4 & $97.1+*$ & 2.9 \\
\hline India & 7.5 & $92.5+$ & $93.8+$ & 6.2 & $88.1+*$ & 11.9 & $86.3+$ & 13.8 \\
\hline
\end{tabular}

Notes. Predicted associations are shown in italic font. The margin of error for any proportion can be calculated as $1.96 \sqrt{p(1-p) / n}$

+This percentage is significantly $(p<.05)$ greater than $50 \%$, according to the chi-square test

*The percentage for this country is significantly $(p<.05)$ higher than the percentage for the other country, according to Fisher's exact test of independence

("Smoke was coming out of his ears"; p. 162). When anger becomes too intense, there is pressure on the container and the person explodes ("She blew up at me"; p. 162). This conceptual metaphor might exist because angry people have increased body temperatures, feel internal pressure, and become red in the neck and face (Kövecses, 2000). In addition, both anecdotal evidence (Schwitzgebel, 2006) and experimental research (Fetterman, Robinson, Gordon, \& Elliot, 2011) indicate that some people literally see red when they are angry. If this conceptual metaphor is indeed based upon physiological changes, then the associations of anger with red and hot may be commonly endorsed in many countries.

Third, we found strong evidence that happiness is associated with up and sadness with down. Across both countries, these associations were endorsed by at least $96 \%$ of participants. This is consistent with previous research in the USA, India, China, France, Germany, Hungary, Israel, Japan, Mayan Indians, Nepal, and Russia (see Table 1). This is also consistent with conceptual metaphor theory, which claims that happiness is associated with up and sadness with down

Table 4 Percentages of people indicating that emotions correspond to each color, Study 1

\begin{tabular}{|c|c|c|c|c|c|c|c|c|c|}
\hline Emotion & Red & Purple & Blue & Green & Yellow & Orange & Black & Gray & White \\
\hline \multicolumn{10}{|c|}{ Happiness } \\
\hline USA & 18.0 & $22.9 *$ & 19.0 & 38.0 & $75.6+*$ & $44.4^{*}$ & 1.5 & 0.5 & 32.7 \\
\hline India & 11.2 & 13.7 & $28.6^{*}$ & 42.9 & 28.0 & 21.7 & 3.7 & $5.6^{*}$ & $53.4 *$ \\
\hline \multicolumn{10}{|l|}{ Sadness } \\
\hline USA & 1.5 & $11.7 *$ & $65.9+*$ & 2.4 & 1.5 & 0.5 & 49.8 & $55.1 *$ & 7.3 \\
\hline India & $9.9^{*}$ & 5.0 & 15.5 & 5.0 & $7.5^{*}$ & 2.5 & $57.1+$ & 30.4 & 8.1 \\
\hline \multicolumn{10}{|l|}{ Anger } \\
\hline USA & $88.3+*$ & 8.3 & 1.5 & 1.0 & 3.9 & $18.0^{*}$ & $37.6^{*}$ & 6.8 & $8.8^{*}$ \\
\hline India & $68.9+$ & 4.3 & $6.8^{*}$ & $5.0^{*}$ & 6.8 & 8.7 & 23.0 & 6.2 & 3.1 \\
\hline \multicolumn{10}{|l|}{ Fear } \\
\hline USA & 10.2 & 10.2 & 14.1 & 6.3 & 13.7 & 5.9 & $57.1+*$ & $39.5^{*}$ & 20.5 \\
\hline India & $20.5^{*}$ & 6.8 & 16.8 & 6.8 & 12.4 & 7.5 & 39.8 & 20.5 & 13.7 \\
\hline
\end{tabular}

Notes. Predicted associations are shown in italic font. The margin of error for any proportion can be calculated as $1.96 \sqrt{p(1-p) / n}$. For each row, the percentages do not add to $100 \%$ because participants were allowed to select multiple colors

+This percentage is significantly $(p<.05)$ greater than $50 \%$ (directional), according to the chi-square test

*The percentage for this country is significantly $(p<.05)$ higher than the percentage for the other country, according to Fisher's exact test of independence 
because of our physical experiences, such as upright posture for happiness and slouching posture for sadness (Lakoff \& Johnson, 1980).

Fourth, we found strong evidence that sadness is associated with empty. At least $91 \%$ of participants in the two countries endorsed this association, consistent with previous research in the USA and Persia (see Table 1). Shweder (1991) says that people in some countries experience depression as emptiness because the physical consequences of depression (loss of sleep, appetite, energy, etc.) are the same as the perceived consequences of emptiness. We believe that sadness may be associated with emptiness because emptiness is associated with the lack of something, which is likely to cause sadness.

Finally, the association of fear with paralysis was endorsed by at least $86 \%$ of participants in the two countries, consistent with previous research in the USA, Persia, Poland, Russia, and the UK (see Table 1). Fear may be associated with paralysis due to people's physiological reaction to fear, which can include an inability to move (Ding, 2012).

Additional research is needed to determine the causes of cross-cultural similarities in the ways emotions are described. Some similarities may be due to direct borrowing: Just as languages borrow individual words (e.g., English borrowed joy, cry, and glorify from French), they also borrow whole phrases (Baker \& Jones, 1998). However, whether the metonymies and conceptual metaphors were originally invented in many languages or just one, this still leaves the question of how these phrases came about in the first place. Lakoff $(2009,2014)$ has postulated that metonymies and conceptual metaphors are possible because physiological sensations often accompany emotional experiences. As William James (1890) said, "What kind of an emotion of fear would be left if the feeling neither of quickened heart-beats nor of shallow breathing, neither of trembling lips nor of weakened limbs, neither of goose-flesh nor of visceral stirrings, were present, it is quite impossible for me to think" (p. 452). Physical experiences like warmth, proximity, height, and movement co-occur with emotional experiences, which causes these sensations to be bound into neural circuits with the emotions themselves (Lakoff, 2009, 2014). These internal sensations can then be used to help understand emotions (Lakoff, 2014; Meier \& Robinson, 2005). Moreover, invoking cognitive structures related to sensations influences emotional reactions and social responses (Fay \& Maner, 2014). For example, social rejection causes lower skin temperatures, but holding a warm cup counteracts the emotional effect of social rejection (Ijzerman et al., 2012), and recalling a nostalgic event makes a cold room feel warmer (Zhou, Wildschut, Sedikides, Chen, \& Vingerhoets, 2012). Thus, the cross-cultural associations of emotions with sensory descriptors may go beyond words to underlying cognitive structures.
In contrast to the ten associations just discussed, some associations may be specific to a few countries or cultures. First, sadness and blue seem to have a country-specific association: Most participants from the USA $(65.9 \%)$ associated sadness with blue, but only a minority of participants from India (15.5 $\%$ ) did so. This was surprising to us, because lexical analyses have shown that sadness is associated with blue in the USA (Apresjan, 1997; Gunther, 2004), China (Tao, Tan, \& Picard, 2005), Finland (Salokangas, Vaahtera, Pacriev, Sohlman, \& Lehtinen, 2002), and among Mayan Indians (Shweder, 1991). Similarly, in Italy, Korea, and Mexico, blue is associated with mourning (Maroto \& De Bortoli, 2001). However, blue is associated with different emotions in other countries. For example, the French phrase "fureur bleue" means to be in a blue fury or to have extreme anger (Kennedy, 2011, French section, line 64) and the phrase "avoir une peur bleue" means to have a blue fear or to be frightened to death (line 67). Blue may be associated with a variety of emotions because the associations are not based upon common physiological reactions. People turn red when they are angry (hence, anger is red), but people do not turn blue when they are sad (Fetterman, Robinson, \& Meier, 2012).

Two additional associations may be culture-specific: Participants in the USA predominately associated happiness with warm and fear with cold, but these associations were not common in India. This finding contradicts previous research demonstrating that people from multiple countries, including India, associate joy with an increase in body temperature and fear with a decrease in body temperature (Scherer \& Wallbott, 1994). However, three meta-analyses (Cacioppo, Bernston, Larsen, Poehlmann, \& Ito, 2000; Kreibig, 2010; Stemmler, 2004) have examined the relationship between emotions and physiological reactions and only one of them (Kreibig, 2010) found that happiness increased facial temperature and fear reduced it. Thus, inconsistencies in the conceptual link between emotions and temperatures may be because these associations are not based upon strong, consistent physiological associations.

One association was not endorsed in either country: Fear is white. This finding contradicts previous research conducted in several countries, which has found that people are said to turn white, blanch, or become pale when they are frightened (Apresjan, 1997; Maalej, 2007; Oster, 2010; Strugielska \& Alonso-Alonso, 2007). For example, the phrase "to whiten" is used in the USA and Russia to indicate fear (Apresjan, 1997, p. 187) and the phrase "his face was white from fright" is used in Persia (Maalej, 2007, p. 98). Examining these phrases in light of our findings, we developed a new hypothesis about the association of white and fear. These sayings appear to be based upon a physiological reaction: When people become scared, the blood drains from their faces, making them appear pale or white (Maalej, 2007). Perhaps fear is only 
associated with looking white, not white in general. We designed Study 2 to investigate this possibility.

\section{Study 2}

\section{Introduction and method}

In Study 1, we based our methodology upon Waggoner's (2010) study, in which participants were simply asked if descriptors corresponded to emotions (e.g., which descriptors does fear correspond to?). However, we now believe there are three ways descriptors might be associated with an emotion: Descriptors might be associated with how an emotion feels, how a person looks when they are feeling an emotion, or the cause of an emotion. Therefore, we revised the LEQ. The LEQ2 has the same items as the LEQ. However, there are now three sections: Which adjective describes how people feel when they experience each emotion, which adjective describes how people look when they experience each emotion, and which adjective describes the cause of each emotion.

Using MTurk, we recruited 214 new participants from the USA and 215 new participants from India. Participants were automatically paid 35 cents for completing the 10-min survey. As in Study 1, we only analyzed the data from participants who were very comfortable with English.

\section{Results and discussion}

The results were essentially the same as in Study 1. In the USA, the majority of participants associated the target emotion with the descriptor for 13 of the 14 metonymies and conceptual metaphors, and in India, the majority did not associate sadness with blue, happiness with warm, or fear with cold (see Tables A, B, and C in the supplementary material).

As predicted, the relationships between fear and white were somewhat different depending upon which prompt was used (see Table 5). Fear was associated more with how someone looked than with how they felt or the cause of the emotion. However, this relationship was not strong: In the USA only $29.9 \%$ and in India only $15.8 \%$ of participants associated fear with looking white. Furthermore, this was not the strongest association for the emotion or the color in either country: As was the case in Study 1, in both countries, fear was more associated with black and gray than white, and looking white was more associated with happiness than fear. Thus, this study found that fear was not commonly associated with looking white in either the USA or India.

Although lexical analyses in several countries associated fear with a white face (see Table 1), other analyses have shown that loss of blood flow is represented by a variety
Table 5 Percentages of participants indicating that emotions correspond to each color, Study 2, selected results

\begin{tabular}{lllllll}
\hline \multirow{3}{*}{ Country } & Prompt & Red & Black & Grey & White & White \\
\cline { 3 - 6 } & & & & \\
USA & Feel & 18.7 & $67.3+^{*}$ & $46.3^{*}$ & $22.0^{*}$ & 43.5 \\
& Look & 12.6 & 49.5 & $49.1^{*}$ & $29.9 *$ & 39.7 \\
& Cause & 15.4 & $64.5+^{*}$ & $52.8^{*}$ & 19.6 & 39.7 \\
India & Feel & 19.1 & 44.2 & 24.7 & 14.0 & 43.3 \\
& Look & 19.5 & 45.6 & 25.6 & 15.8 & 43.3 \\
& Cause & 15.8 & 50.7 & 21.4 & 14.4 & 39.1 \\
\hline
\end{tabular}

Notes. Predicted associations are shown in italic font. The margin of error for any proportion can be calculated as $1.96 \sqrt{p(1-p) / n}$. For each row, the percentages do not add to $100 \%$ because participants were allowed to select multiple colors and because additional colors were given, beyond those shown here

Look $=$ participants were asked how people look when they experience each emotion

Feel $=$ participants were asked how people feel when they experience each emotion

Cause $=$ participants were asked what describes the cause of each emotion + This percentage is significantly $(p<.05)$ greater than $50 \%$ (directional), according to the chi-square test

*For this prompt and descriptor, the percentage for this country is significantly $(p<.05)$ higher than the percentage for the other country, according to Fisher's exact test of independence

of colors depending upon the culture, including "paleness, whiteness, yellowness, blueness, etc." (Maalej, 2007, p. 93). The lack of specificity for the appearance of fear echoes previous work on the recognition of fear. In some cultures, facial expressions for fear are not as well recognized as facial expressions for other emotions (Ekman \& Friesen, 1971; Matsumoto \& Ekman, 1989). We therefore conclude there is no single association between fear and how someone looks: Saying that someone looks white or has a white face is not a universal and unambiguous way of saying that they are scared.

\section{General discussion}

The purpose of this research was to determine if certain descriptors have consistent associations with happiness, sadness, anger, and fear, so that they could be used in psychological tests without causing confusion to test takers. For most of our hypotheses, significantly more than $50 \%$ of participants in both countries selected the hypothesized descriptors. This provides support for the universality of many of these associations. The strongest support was for the associations of happiness with up and bright. These associations were universal (found in both the USA and India), ubiquitous (endorsed by 
more than $90 \%$ of participants in those countries), and unique (those descriptors were not commonly associated with any of the other emotions we tested). Given the strength of these associations, we conclude that $u p$ and bright are unambiguously associated with happiness in the USA and India, and can be used on psychological tests without being likely to cause confusion.

However, even when most participants agreed with a particular association, the percentages were frequently far below $100 \%$. For example, in the USA, only $71.7 \%$ associated hot with anger and only $65.9 \%$ associated blue with sadness. Moreover, descriptors were often associated with multiple emotions, making them ambiguous. For example, almost all participants in the USA associated dark with fear, sadness, and anger (reinforcing previous research showing that negative emotions in general are associated with dark; Barcelona, 2003). Even when only a single emotion was hypothesized to be associated with a descriptor, multiple associations were sometimes found. For example, participants from the USA associated paralyzed with sadness and anger as well as fear, and associated down with fear and anger as well as sadness. Thus, the associations between emotions and descriptors were usually not one-to-one in the USA.

In addition, the percentage of people who endorsed the hypothesized associations was uniformly smaller in India than in the USA. For nine of these associations, the difference in the percentages was statistically significant. For three (happiness with warm, fear with cold, and sadness with blue), the percentage was less than $50 \%$ in India. The lower percentages for India were expected, because we originally selected these 14 emotion-descriptor pairs based upon evidence that came primarily from the USA. However, these lower percentages provide a strong warning to test designers: Figurative language will probably be understood by fewer people when it is used in another country or culture.

The differences between India and the USA are likely even larger than they appear to be in this study. Recall that we filtered our participants. To ensure that participants understood the instructions and the items, we only analyzed data from people who indicated that they were very comfortable with reading, writing, speaking, and listening to English. Because of these strict criteria, we filtered out almost $75 \%$ of the participants from India. Previous research has shown that bilingual people who are very fluent with a language interpret metaphors in a way that is more similar to monolinguals in that language and that the language used during a study influences how bilinguals think about metaphors (Lai \& Boroditsky, 2013). Thus, using English-language materials to test participants who are very comfortable with English created a conservative test for differences between the groups. The differences between the populations of English-speaking people from India and the USA are likely larger than shown here.
Additionally, the use of closed-ended questions may have made the USA and India appear more similar than they truly are and may have made the associations between emotions and descriptors appear stronger than they are. It might be that some (or even most) participants associate some of the descriptors with emotions that were not included in our response options. For example, perhaps many people associate up or bright with pride or excitement. If so, then the associations of $u p$ and bright with happiness are not unique. Moreover, if people in one country associate $u p$ with pride and people in another country associate $u p$ with excitement, then people in the two countries would not interpret the word $u p$ in the same way. These limitations make the similarities we found less conclusive but make the differences even more impressive. Future research on the emotional associations of descriptors should, at the minimum, include a longer list of possible emotions. Ideally, this research should use open-ended questions.

Future research should examine additional samples. Our two studies examined MTurk users who are very comfortable with English. However, sound conclusions about each culture and sound comparisons across cultures require data collection from multiple groups within each culture (Matsumoto \& Yoo, 2007). Therefore, before concluding that the English words up and bright are universally and uniquely associated with happiness (and that other descriptors are not unambiguously associated with particular emotions), other types of participants should be examined in the USA and India (e.g., managers and students, teenagers and retirees, and specific ethnic groups) and in other countries and cultures. Furthermore, future research should include additional languages, especially ones where the lexical space for emotions is quite different. This is important both for the integrity of tests that were initially developed in those languages and for the validity of tests that were translated from English.

Given that only two of the 14 associations were universal, ubiquitous, and unique, we conclude that most figurative language is likely to be ambiguous and cause confusion among test takers, both in the culture in which the test was developed and even more so if the test is used in another culture (either in its original language or when translated). In particular, the use of blue (CES-D; Eaton et al., 2004; Radloff, 1977; and PANAS-X; Watson \& Clark, 1994; Watson et al., 1988) and downhearted (PANAS-X) as synonyms for sadness appears to be problematic, especially because these words are presented in isolation on the PANAS-X, with no context that might allow readers to infer their meaning. The phrases wound up (Beck Depression Inventory; Beck, 1972), short-tempered (Hogan's Empathy Scale; Hogan, 1969), sluggish, and sheepish (PANAS-X; Watson \& Clark, 1994; Watson et al., 1988) might also be interpreted inconsistently by test takers. Circumstantial evidence for problems with these items is given by factor analytic results. None of the four figurative words from the PANAS-X were included in the 20-item version of 
the PANAS (Watson et al., 1988), which was based upon factor analyses of the PANAS-X. Also, none survived translation and factor analyses to be included on the 42-item Estonian General Affect Scale, which was modeled after the PANAS-X (Allik \& Realo, 1997).

Future research should explicitly examine how people interpret figurative language that appears on tests related to emotions (e.g., depression, emotion perception, emotional expressiveness, or emotional control). Researchers can ask test takers how they interpret specific items. Perhaps readers will be better able to interpret that figurative language given the context in which it appears (i.e., as part of a sentence-length item, and as part of a test related to emotions). Ideally, researchers should use semi-structured interviews with openended questions to explore the conceptual equivalence of these items across individuals and across cultures (see e.g., Corral \& Landrine, 2009; Matsumoto \& Yoo, 2007).

One such qualitative analysis was completed by HaboushDeloye (2013) for tests of emotion suppression and found many differences in the interpretation of items containing figurative language. For example, participants were asked how they interpreted the item, "I try to control unpleasant emotions and strengthen positive ones" (an item that occurs on the Emotional Skills and Competence Questionnaire; Takšić, 2005). Participants with an individualistic worldview defined control as not letting others see the feeling, whereas those with a collectivist worldview defined control as managing the emotions so they are not controlling the person. Later, participants were asked how they would interpret the item, "When I am anxious, I smother my feelings" (an item that occurs on the Courtauld Emotional Control Scale; Watson \& Greer, 1983). Several participants said they were unsure how to interpret the word smother in the context of the question. Of those who could define smother, the majority said that smother meant to hide emotions from others, but some said it meant to hide the emotions from oneself. Thus, figurative language was interpreted differently both between and within cultural groups. Future researchers should look for such differences in interpretation.

In addition, researchers should explicitly test whether people from different countries and cultures score differently on items that include figurative language. For example, the Mayer-Salovey-Caruso Emotional Intelligence Test (Mayer, Caruso, \& Salovey, 2000) contains a section that tests knowledge of sensations that are associated with emotions. Many of those associations appear to be figurative rather than literal (for example, no emotion is literally "sharp," "dark," or "closed"). If those figurative associations vary from one country or culture to the next, that section could provide systematically lower scores for people who are not from the USA (where the test was developed and normed). Researchers should therefore test whether differences between countries (and between cultural minorities and cultural majorities in the USA) are larger on these items than on other parts of the test.
Our findings also have practical implications: Test users should be cautious in using existing tests that contain figurative language. If a test contains many items, then the presence of a single confusing item is not likely to have a large effect on test scores. The problems are likely to be greatest if several items contain figurative language (e.g., the PANAS-X contains four such items) or if a short form is being used. Clinicians should be particularly careful if they are interpreting the scores for individual test takers and the initial scores are close to a cut-off point. Under these circumstances, clinicians should assess their clients' interpretation of items containing figurative language.

Finally, the problems with figurative language likely generalize to content areas besides emotions: Even if a phrase is common, it may not be universally understood. For example, in the USA, sharp is figurative language for intelligence and driven is figurative language for motivation. However, if sharp and driven do not have those same meanings in other countries or cultures, using these words to denote intelligence and motivation on psychological tests could cause confusion among test takers and result in test bias. This is true even if the test will be used exclusively in the USA, given the number of overlapping subcultures that exist here. If test designers want to use figurative language on a test of any psychological construct, they must ensure that the concepts that underlie the words have the same meaning in different countries and cultures (Matsumoto \& Yoo, 2007). In the absence such evidence, test users should be aware of possible test bias on items containing figurative language and test designers should be cautious using figurative language when designing new tests.

Acknowledgments The authors wish to thank the following people for their feedback on earlier drafts of this paper: Maria Gendron, Northeastern University; Junqing Chen, City University of New York; Alexis Kennedy, Laurel Pritchard, and Erin Hannon from the University of Nevada, Las Vegas (UNLV); members of the UNLV Psychology Writing Workshop; and members of the UNLV Interactive Measurement Group.

\section{References}

Aiken, L. R., \& Groth-Marnat, G. (2006). Psychological testing and assessment (12th ed.). Boston: Allyn and Bacon.

Allik, J., \& Realo, A. (1997). Emotional experience and its relation to the five-factor model in Estonian. Journal of Personality, 65, 625-647. doi:10.1111/j.1467-6494.1997.tb00329.x647

Amazon Web Services (2014). Amazon Mechanical Turk Requester UI Guide. Retrieved from http://docs.aws.amazon.com/ AWSMechTurk/latest/RequesterUI/Welcome.html

Antin, J., \& Shaw, A. (2012) Social desirability bias and self-reports of motivation: A study of Amazon Mechanical Turk in the US and India. Presented at Association for Computing Machinery SIGCHI Conference on Human Factors in Computing Systems, Austin, TX.

Apresjan, V. (1997). Emotion metaphors and cross-linguistic conceptualization of emotions. Cuadernos de Filologia Inglesa, 6, 179-196. 
Baker, C., \& Jones, S. P. (Eds.). (1998). Encyclopedia of bilingualism and bilingual education. Clevedon: Multilingual Matters.

Barbee, E. L. (2009). Healing time: The blues and African-American women. Health Care for Women International, 15, 53-60. doi:10. 1080/07399339409516094

Barcelona, A. (2003). Metaphor and metonymy at the crossroads: A cognitive perspective (2nd ed.). Berlin: Mouton de Gruyter.

Beck, A. T. (1972). Depression: Causes and treatment. Philadelphia: University of Pennsylvania Press.

Buhrmester, M., Kwang, T., \& Gosling, S. D. (2011). Amazon's Mechanical Turk: A new source of inexpensive, yet high-quality, data? Perspectives on Psychological Science, 6, 3-5. doi:10.1177/ 1745691610393980

Cacioppo, J. T., Bernston, G. G., Larsen, J. T., Poehlmann, K. M., \& Ito, T. A. (2000). The psychophysiology of emotion. In R. Lewis \& J. M. Haviland-Jones (Eds.), The handbook of emotion (2nd ed., pp. 173-191). New York: Guildford Press.

Census of India (2011). Population enumeration data. [Data file]. Retrieved from http://censusindia.gov.in/2011-prov-results/ indiaatglance.html

Chand, V. (2008). Fire and hot liquids: Anger in Hindi and English. In F. Boers, J. Darquennes, K. Kerremans, \& R. Temmerman (Eds.), Multilingualism and applied comparative linguistics volume 2 (pp. 2-23). Newcastle: Cambridge Scholars Publishing.

Chen, P. (2010). A cognitive study of "happiness" metaphors in English and Chinese idioms. Asian Culture and History, 2, 172-175. doi:10. 5539/ach.v2n2p172

Chen, J., Kacinik, N. A., Chen, Y., \& Wu, N. (2014). Metaphorical color representations of emotional concepts in English and Chinese speakers: Evidence from behavioral data. Poster session presented at Society for Personality and Social Psychology conference, Long Beach, CA.

Cohen, J. (1992). A power primer. Psychological Bulletin, 112, 155-159. doi:10.1037//0033-2909.112.1.155

Corral, I., \& Landrine, H. (2009). Methodological and statistical strategies in research with diverse samples. The problem of measurement equivalence. In H. Landrine \& N. F. Russ (Eds.), Handbook of diversity in feminist psychology (pp. 83-134). New York: Springer.

Danesi, M. (1992). Metaphorical competence in second language acquisition and second language teaching: The neglected dimension. In J. E. Alatis (Ed.), Georgetown University Round Table on Languages and Linguistics 1992. Washington, D.C.: Georgetown University Press.

Davitz, J. R. (1969). The language of emotion. New York: Academic Press.

Deignan, A. (2005). A corpus linguistic perspective on the relationship between metonymy and metaphor. Style, 39, 72-91.

Department of Official Language (2011). The official languages: Use for official purpose of the union (4th ed.). Retrieved from http://www. rajbhasha.nic.in/UI/pagecontent.aspx?pc $=$ Mzk\%3d

Ding, F. (2012). The interaction between metaphor and metonymy in emotion category. Theory and Practice in Language Studies, 2, 2384-2397. doi:10.4304/tpls.2.11.2384-2397

Dobrovol'skiū, D., \& Piirainen, E. (2005). Figurative language: Crosscultural and cross-linguistic perspectives. Oxford: Elsevier.

Dor-Shav, N. K., \& Dor-Shav, Z. (1978). Cross-cultural study of ratings of phenomenological experience of emotion. Psychological Reports, 42, 583-590. doi:10.2466/pr0.1978.42.2.583

Eaton, W. W., Muntaner, C., Smith, C., Tien, A., \& Ybarra, M. (2004). Center for Epidemiologic Studies Depression Scale: Review and revision (CESD and CESD-R). In M. E. Maruish (Ed.), The use of psychological testing for treatment planning and outcomes assessment (3rd ed., pp. 362-377). Mahwah: Lawrence Erlbaum.

Ekman, P., \& Friesen, W. V. (1971). Constants across cultures in the face and emotion. Journal of Personality and Social Psychology, 17, 124-129. doi:10.1037/h0030377
Fainsilber, L., \& Ortony, A. (1987). Metaphorical uses of language in the expression of emotions. Metaphor and Symbolic Activity, 24, 239 250. doi:10.1207/s15327868ms0204 2

Fay, A. J., \& Maner, J. K. (2014). Embodied effects are moderated by situational cues: Warmth, threat, and the desire for affiliation. British Journal of Social Psychology, 54, 291-305. doi:10.1111/bjso.12088

Ferro-Luzzi, G. E. (1995). The culture-free construction of emotion. A Tamil writer's emotion similes and metaphors. Anthropos, 90, 185192.

Fetterman, A. K., Robinson, M. D., Gordon, R. D., \& Elliot, A. J. (2011). Anger as seeing red: Perceptual sources of evidence. Social Psychological \& Personality Science, 2, 311-316. doi:10.1177/ 1948550610390051

Fetterman, A. K., Robinson, M. D., \& Meier, B. P. (2012). Anger as "seeing red": Evidence for a perceptual association. Cognition and Emotion, 26, 1445-1458. doi:10.1080/02699931.2012.673477

Gibbs, R. W., Jr. (1994). The poetics of mind: Figurative thought, language, and understanding. Cambridge: Cambridge University Press.

Gunther, Y. H. (2004). The phenomenology and intentionality of emotion. Philosophical Studies, 117, 43-55. doi:10.1023/B:PHIL. $0000014524.65244 .9 \mathrm{~d}$

Gupta, N., Martin, D., Hanrahan, B. V., \& O'Neill, J. (2014). Turk-life in India. Presentation at Association for Computing Machinery convention, Sanibel Island, FL. doi:10.1145/2660398.2660403

Haboush-Deloye, A. (2013). Assessing conceptual equivalence of measures of suppression in diverse populations [Doctoral dissertation]. Retrieved from http://digitalscholarship.unlv.edu/thesesdissertations/ $1831 /$

Hofstede, G. (1983). The cultural relativity of organizational practices and theories. Journal of International Business Studies, 14, 75-89. doi:10.1057/palgrave.jibs. 8490867

Hogan, R. (1969). Development of an empathy scale. Journal of Consulting and Clinical Psychology, 33, 307-316. doi:10.1037/ h0027580

Hogan, T. P. (2015). Psychological testing: A practical introduction (3rd ed.). Hoboken: Wiley.

Hurtienne, J., Stößel, C., \& Weber, K. (2009). Sad is heavy and happy is light: Population stereotypes of tangible object attributes. Proceedings of the 3rd International Conference on Tangible and Embedded Interaction, United Kingdom (pp. 61-68). New York: Association for Computing Machinery. doi:10.1145/1517664. 1517686

Ijzerman, H., Gallucci, M., Pouw, W. T., Weißgerber, S. C., Van Doesum, N. J., \& Williams, K. D. (2012). Cold-blooded loneliness: Social exclusion leads to lower skin temperatures. Acta Psychologica, 140, 283-288. doi:10.1016/j.actpsy.2012.05.002

James, W. (1890). The principles of psychology (Vol. 2). London: Macmillan.

Kaviani, H., \& Hamedi, R. (2011). A quantitative/qualitative study on metaphors used by Persian depressed patients. Archives of Psychiatry and Psychotherapy, 4, 5-13.

Kaya, N., \& Epps, H. H. (2005). Color-emotion associations: Past experience and personal preference. In J. L. Caivano (Ed.), AIC 2004 Color and Paints, Proceedings of the Interim Meeting of the International Color Association (pp. 31-34). Porto Alegre, Brazil Retrieved from http://www.fadu.uba.ar/sitios/sicyt/color/aic2004/ 031-034.pdf

Kennedy, A. S. (2011). Color idioms in different languages. In Alan S. Kennedy's color/language project. Retrieved from http://www. starchamber.com/colors/color-idioms.html

Khajeh, Z., Ho-Abdullah, I., \& Hua, T. K. (2013). Emotional temperament in food-related metaphors: A cross-cultural account of the conceptualizations of sadness. International Journal of Applied Linguistics \& English Literature, 2, 54-62. doi:10.7575/aiac.ijalel. v. 2 n. 6 p. 54 
Kline, T. J. B. (2005). Psychological testing: A practical approach to design and evaluation. Thousand Oaks: Sage.

Kövecses, Z. (1986). Metaphors of anger, pride, and love: A lexical approach to the structure of concepts. In Pragmatics and Beyond, VII:8. Amsterdam: John Benjamins.

Kövecses, Z. (1990). Emotion concepts. New York: Springer-Verlag.

Kövecses, Z. (1991). Happiness: A definitional effort. Metaphor and Symbolic Activity, 6, 29-46. doi:10.1207/s15327868ms0601 2

Kövecses, Z. (2000). The concept of anger: Universal or culture specific? Psychopathology, 33, 159-170. doi:10.1159/000029139

Kövecses, Z. (2005). Metaphor in culture. New York: Cambridge University Press.

Kövecses, Z. (2009). Metaphor: A practical introduction (2nd ed.). New York: Oxford University Press.

Kövecses, Z. (2013). The metaphor-metonymy relationship: Correlation metaphors are based on metonymy. Metaphor \& Symbol, 28, 75-88. doi: $10.1080 / 10926488.2013 .768498$

Kreibig, S. D. (2010). Autonomic nervous system activity in emotion: A review. Biological Psychology, 84, 394-421. doi:10.1016/j. biopsycho.2010.03.010

Kubiszyn, T., \& Borich, G. (2007). Educational testing and measurement: Classroom application and practice (8th ed.). Hoboken: Wiley.

Lai, V. T., \& Boroditsky, L. (2013). The immediate and chronic influence of spatio-temporal metaphors on the mental representations of time in English, Mandarin, and Mandarin-English speakers. Frontiers in Psychology, 4, 142. doi:10.3389/fpsyg.2013.00142

Lakoff, G. (2009). The neural theory of metaphor. SSRN Electronic Journal. doi:10.2139/ssrn.1437794

Lakoff, G. (2014). Mapping the brain's metaphor circuitry: Metaphorical thought in everyday reason. Frontiers in Human Neuroscience, 8 , 958. doi:10.3389/fnhum.2014.00958

Lakoff, G., \& Johnson, M. (1980). Metaphors we live by. Chicago: University of Chicago Press.

Lakoff, G., \& Kövecses, Z. (1987). The cognitive model of anger inherent in American English. In D. Holland \& N. Quinn (Eds.), Cultural models in language and thought (pp. 195-221). Cambridge: Cambridge University Press.

Li, X. (2010). A comparative analysis of English and Chinese idioms: From the perspective of conceptual metaphor of "happiness". Journal of Language Teaching \& Research, 1, 473-476. doi:10. 4304/jitr.1.4.473-476

Litman, L., Robinson, J., \& Rosenzweig, C. (2015). The relationship between motivation, monetary compensation, and data quality among US- and India-based workers on Mechanical Turk. Behavior Research Methods, 47, 519-528. doi:10.3758/s13428014-0483-x

Liu, X., \& Zhao, G. (2013). A comparative study of emotion metaphors between English and Chinese. Theory and Practice in Language Studies, 3, 155-162. doi:10.4304/tpls.3.1.155-162

Lovett, R. (2013). 20 British words that mean something totally different in the U.S. [Web blog post]. Retrieved from http://www. bigstockphoto.com/blog/20-british-words-that-mean-somethingtotally-different-in-the-us

Luodonpää-Manni, M., \& Viimaranta, J. (2010). Metaphoric expressions on vertical axis revisited: An empirical study of Russian and French material. Metaphor and Symbol, 25, 74-92. doi:10.1080/ 10926481003715994

Maalej, Z. (2007). The embodiment of fear expressions in Tunisian Arabic: Theoretical and practical implications. In F. Sharifian \& G. B. Palmer (Eds.), Applied cultural linguistics: Second language teaching/learning and intercultural communication (pp. 87-104). Amsterdam: John Benjamins. doi:10.1075/celcr.7.07maa

Maroto, J., \& De Bortoli, M. (2001). Translating colours in web site localization. In Proceedings of the European Languages and the Implementation of Communication and Information Technologies
(Elicit) Conference, United Kingdom. Retrieved from http:// globalpropaganda.com/articles/TranslatingColours.pdf

Mason, W., \& Suri, S. (2011). Conducting behavioral research on Amazon's Mechanical Turk. Behavior Research Methods, 44, 123. doi:10.3758/s13428-011-0124-6

Matsuki, K. (1995). Metaphors of anger in Japanese. In J. R. Taylor \& R. E. MacLaury (Eds.), Language and the Cognitive Construal of the World (pp. 137-151). Berlin: de Gruyter.

Matsumoto, D., \& Ekman, P. (1989). American-Japanese cultural differences in intensity ratings of facial expressions of emotion. Motivation and Emotion, 13, 143-157. doi:10.1007/bf00992959

Matsumoto, D., \& Yoo, S. (2007). Methodological considerations in the study of emotion across cultures. In J. A. Coan \& J. J. B. Allen (Eds.), Handbook of emotion elicitation and assessment (pp. 332348). New York: Oxford University Press.

Mayer, J. D., Caruso, D. R., \& Salovey, P. (2000). Emotional intelligence meets traditional standards for an intelligence. Intelligence, 27, 267298. doi:10.1016/S0160-2896(99)00016-1

McIntire, S. A., \& Miller, L. A. (2007). Foundations of psychological testing: A practical approach (2nd ed.). Thousand Oaks: Sage.

McMullen, L. M., \& Conway, J. B. (2002). Conventional metaphors for depression. In S. Fussel (Ed.), The verbal communication of emotions: Interdisciplinary perspectives (pp. 167-181). Mahwah: Erlbaum.

Meier, B. P., \& Robinson, M. D. (2005). The metaphorical representation of affect. Metaphor and Symbol, 20, 239-257. doi:10.1207/ s15327868ms2004_1

Mikolajczuk, A. (1998). The metonymic and metaphoric conceptualization of 'anger' in Polish. In A. Athanasjadou \& E. Tabakowska (Eds.), Speaking of emotions: Conceptualization and expression (pp. 153-191). Berlin: Mouton.

Moradi, M. R., \& Mashak, S. P. (2013). A comparative and contrastive study of sadness conceptualization in Persian and English. English Linguistics Research, 2, 107-112. doi:10.5430/elr.v2n1p107

Omori, A. (2008). Emotion as a huge mass of moving water. Metaphor and Symbol, 23, 130-146. doi:10.1080/10926480801944277

Oster, U. (2010). Using corpus methodology for semantic and pragmatic analyses: What can corpora tell us about the linguistic expression of emotions? Cognitive Linguistics, 21, 727-763. doi:10.1515/COGL. 2010.023

Paolacci, G., \& Chandler, J. (2014). Inside the turk: Understanding Mechanical Turk as a participant pool. Current Directions in Psychological Science, 23, 184-188. doi:10.1177/0963721414531598

Partridge, E. (2006). A dictionary of slang and unconventional English. Abingdon: Routledge.

Porter, J. (1807). Aphorisms of Sir Philip Sidney: With Remarks (Vol. 2, p. 81). London, England: Longman, Hurst, Rees, and Orme. Retrieved from http://books.google.com/books?oe=UTF-8\&id=

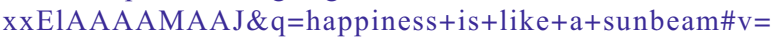
onepage $\& \mathrm{q} \& \mathrm{f}=$ false

Pritzker, S. (2003). The role of metaphor in culture, consciousness, and medicine: A preliminary inquiry into the metaphors of depression in Chinese and Western medical and common languages. Clinical Acupuncture \& Oriental Medicine, 4, 11-28. doi:10.1016/S14611449(02)00013-0

Radloff, L. S. (1977). The CES-D Scale: A self-report depression scale for research in the general population. Applied Psychological Measurement, 1, 385-401. doi:10.1177/014662167700100306

Rand, D. G. (2012). The promise of Mechanical Turk: How online labor markets can help theorists run behavioral experiments. Journal of Theoretical Biology, 299, 172-179. doi:10.1016/j.jtbi.2011.03.004

Ross, J., Irani, I., Silberman, M. S., Zaldivar, A., \& Tomlinson, B. (2010). Who are the crowdworkers?: Shifting demographics in Amazon Mechanical Turk. CHI EA '10: Proceedings of the ACM Conference on Human Factors in Computing Systems 2863-2872. doi: $10.1145 / 1753846.1753873$ 
Ruben, B. D. (1985). The coming of the information age: Information, technology, and the study of behavior. Information and Behavior, 1 . New Brunswick: Transaction Books.

Russell, J. A. (1991). Culture and the categorization of emotions. Psychological Bulletin, 110, 426-450. doi:10.1037//0033-2909. 110.3.426

Salkind, N. J. (2006). Tests and measurement for people who (think they) hate tests and measurement. Thousand Oaks: Sage.

Salokangas, R. K., Vaahtera, K., Pacriev, S., Sohlman, B., \& Lehtinen, V. (2002). Gender differences in depressive symptoms: An artefact caused by measurement instruments? Journal of Affective Disorders, 68, 215-220. doi:10.1016/S0165-0327(00)00315-3

Sandford, J. L. (2014). Turn a colour with emotion: A linguistic construction of colour in English. Journal of the International Colour Association, 13, 67-83.

Scherer, K. R., \& Wallbott, H. G. (1994). Evidence for universality and cultural variation of differential emotion response patterning. Journal of Personality and Social Psychology, 66, 310-328. doi: 10.1037/0022-3514.66.2.310

Schwitzgebel, E. (2006). Do some people literally see red when they're angry? [Web log post]. Retrieved from http://schwitzsplinters. blogspot.com/2006/04/do-some-people-literally-see-red-when_27.html

Shweder, R. A. (1991). Thinking through cultures: Expeditions in cultural psychology. Cambridge: Harvard University Press.

Soriano, C., \& Valenzuela, J. (2009). Emotion and colour across languages: Implicit associations in Spanish colour terms. Social Science Information, 48, 421-445. doi:10.1177/0539018409106199

Sprouse, J. (2011). A validation of Amazon Mechanical Turk for the collection of acceptability judgments in linguistic theory. Behavior Research Methods, 43, 155-167. doi:10.3758/s13428-010-0039-7

Stemmler, G. (2004). Physiological processes during emotion. In P. Philippot \& R. S. Feldman (Eds.), The regulation of emotion (pp. 33-70). Mahwah: Lawrence Erlbaum.

Strugielska, A., \& Alonso-Alonso, M. R. (2007). Idiomatic expressions in multicultural integration: A cross-linguistic perspective. In A. Cervantes-Carson \& I. Lazaroms (Eds.), The politics of multiculturalism: Questions across disciplines. Oxford: Inter-Disciplinary Press.

Sun, H. (2010). The cognitive study of metaphor and its application in English language teaching. Canadian Social Science, 6, 175-179

Takšić, V. (2005). Basic psychometric properties of Emotional Skills and Competence Questionnaire (ESCQ) in Croatian samples. Oral presentation in the Symposium Cross-cultural validation of Emotional Skills and Competence Questionnaire (ESCQ) at the 9th European Congress of Psychology, Granada, Spain.

Tao, J., Tan, T., \& Picard, R. W. (2005). Affective computing and intelligent interaction. Berlin: Springer-Verlag.

Tendahl, M., \& Gibbs, R. W., Jr. (2008). Complementary perspectives on metaphor: Cognitive linguistics and relevance theory. Journal of Pragmatics, 40, 1823-1864. doi:10.1016/j.pragma.2008.02.001
Tolaas, J. (1991). Notes on the origin of some spatialization metaphors. Metaphor and Symbolic Activity, 6, 201-218. doi:10.1207/ s15327868ms0603 4

United States Census Bureau (2012a). Table 53. Languages spoken at home: 2009. Retrieved from http://www.census.gov/compendia/ statab/2012/tables/12s0053.pdf

United States Census Bureau (2012b). Section 1: Population. In The 2012 Statistical Abstract. Retrieved from http://www.census.gov/ compendia/statab/2012edition.html

Waggoner, J. E. (2010). Temperature-based metonymies for emotions in children and adults. Psychological Reports, 106, 233-245. doi:10. 2466/PR0.106.1.233-245

Waggoner, J. E., \& Palermo, D. S. (1989). Betty is a bouncing bubble: Children's comprehension of emotion-descriptive metaphors. Developmental Psychology, 25, 152-163. doi:10.1037/0012-1649. 25.1.152

Waggoner, J. E., \& Palermo, D. S. (1991). Contextual and linguistic factors in children's comprehension of emotional metaphors. Paper presented at the annual meeting of the Southeastern Psychological Association, New Orleans, LA.

Wang, D., Wang, J., \& Xing, M. (2011). Metaphorical thinking in English and Chinese languages. Asian Culture and History, 3, 9-12. doi:10. 5539/ach.v3n2p9

Watson, D., \& Clark, L. A. (1994). Manual for the Positive and Negative Affect Schedule - Expanded Form. Iowa City: The University of Iowa.

Watson, M., \& Greer, S. (1983). Development of a questionnaire measure of emotional control. Journal of Psychosomatic Research, 27(4), 299-305. doi:10.1016/0022-3999(83)90052-1

Watson, D., Clark, L. A., \& Tellegan, A. (1988). Development and validation of brief measures of positive and negative affect: The PANAS scales. Journal of Personality and Social Psychology, 54, 1063-1070. doi:10.1037/0022-3514.54.6.1063

$\mathrm{Yu}$, N. (1995). Metaphorical expression of anger and happiness in English and Chinese. Metaphor and Symbolic Activity, 10, 223-245. doi:10. 1207/s15327868ms1002_1

Yu, N. (1998). The contemporary theory of metaphor: A perspective from Chinese language. Philadelphia: John Benjamins North America.

Yu, N. (2002). Body and emotion: Body parts in Chinese expression of emotion. Pragmatics and Cognition, 10, 341-367. doi:10.1075/pc. 10.12.14yu

Zavyalova, N. (2013). Socio-cultural acquisition through idiomatic representation. World Applied Sciences Journal, 27, 445-449. doi:10. 5829/idosi.wasj.2013.27.elelc.91

Zhou, X., Wildschut, T., Sedikides, C., Chen, X., \& Vingerhoets, A. J. (2012). Heartwarming memories: Nostalgia maintains physiological comfort. Emotion, 12, 678-684. doi:10.1037/ a0027236 